\title{
Activities in Namibia to Limit the Prevalence and Mortality from COVID- 19 Including Community Pharmacy Activities and the Implications
}

\section{Dan Kibuule ${ }^{1}$, Lahya Nambahu ${ }^{1}$, Israel Abebrese Sefah ${ }^{2,3}$, Amanj Kurdi ${ }^{4,5}$, Thuy Nguyen Thi Phuong ${ }^{6}$, Hye-Young} Kwon ${ }^{7}$, Brian Godman ${ }^{4,8,9^{*}}$

\author{
${ }^{1}$ Department of Pharmacy Practice and Policy, Faculty of Health Sciences, University of Namibia, Windhoek, Namibia \\ ${ }^{2}$ Pharmacy Department, Keta Municipal Hospital, Ghana Health Service, Keta-Dzelukope, Ghana \\ ${ }^{3}$ Pharmacy Practice Department of Pharmacy Practice, School of Pharmacy, University of Health and Allied Sciences, Volta Region, \\ Ghana \\ ${ }^{4}$ Strathclyde Institute of Pharmacy and Biomedical Sciences, University of Strathclyde, Glasgow G4 ORE, United Kingdom \\ ${ }^{5}$ Department of Pharmacology, College of Pharmacy, Hawler Medical University, Erbil, Iraq \\ ${ }^{6}$ Pharmaceutical Administration \& Pharmaco Economics, Hanoi University of Pharmacy, Vietnam \\ ${ }^{7}$ Division of Biology and Public Health, Mokwon University, Daejeon, South Korea \\ ${ }^{8}$ School of Pharmacy, Sefako Makgatho Health Sciences University, Ga-Rankuwa, Pretoria, 0208, South Africa \\ ${ }^{9}$ School of Pharmaceutical Sciences, Universiti Sains Malaysia, Penang, Malaysia
}

DOI: $10.36347 /$ sajp.2021.v10i05.001

| Received: 05.04.2021 | Accepted: 10.05.2021 | Published: 16.05.2021

*Corresponding author: Brian Godman

Abstract

Original Research Article

Considerable differences exist in prevalence and mortality rates from COVID-19 across countries due to the extent of prevention measures instigated and their timeliness. There has been considerable controversy surrounding hydroxychloroquine, with resultant misinformation increasing medicine prices and suicides. Prices have also increased for Personal Protective Equipment (PPE). There are also growing concerns regarding the unintended consequences from COVID-19 including patients with non-communicable diseases. Consequently, a need to investigate key areas and the preparedness of community pharmacists, who play a key role in Namibia and the wider global community to provide future direction. In view of this, we sought to assess changes in utilisation, prices and shortages of relevant medicines early in the pandemic in Namibia combined with the preparedness of community pharmacists to deal with key issues to guide future activities. This was achieved via a questionnaire survey among '55 pharmacists and assistants from March to end June 2020 including suggestions on potential ways forward and comparisons with other African and Asian countries. We found limited increases in the utilisation of antimalarials and antibiotics in Namibia versus Bangladesh, Ghana, and Nigeria, enhanced by restrictions on self-purchasing in Namibia reflected by limited price rises and shortages. This is encouraging. Higher use of vitamin c and immune boosters in Ghana and Nigeria versus Namibia reflected in higher price rises, with increased utilisation and prices of PPE across a range of African and Asian countries. Encouragingly limited increases in herbal medicine use in Namibia. Future roles of community pharmacists in pandemics include education, good stock control, and screening. More research is needed assessing the unintended consequences of COVID-19.

Keywords: Antimicrobials, COVID-19, Namibia, prices, self-purchasing, unintended consequences.

Copyright $(\mathcal{C} 2021$ The Author(s): This is an open-access article distributed under the terms of the Creative Commons Attribution 4.0 International License (CC BY-NC 4.0) which permits unrestricted use, distribution, and reproduction in any medium for non-commercial use provided the original author and source are credited.

\section{INTRODUCTION}

Corona virus (COVID-19) is a disease caused by the novel corona virus, SARS COV-2, first reported in Wuhan China in December [1], and subsequently spread to all countries and continents [2]. By 8 November 2020, there were 49.73 million reported cases worldwide with more than 1.248 million deaths attributable to COVID-19 giving a case fatality ratio (CFR) of $2.51 \%$ [2]. However, prevalence and mortality rates vary considerably across countries in part affected by the extent and depth of preventative measures instigated at the start of the pandemic coupled with the accuracy of reported cases [3-8].

There are currently no recommended medicines for preventing and treating patients with COVID-19 apart from immune modulators including dexamethasone and tocilizumab following the findings from the UK Recovery and other trials [9-12]. In addition, vaccines against COVID-19 are now being rolled out across countries to reduce the spread of the virus [13-15]. However, whilst the vaccines are being 
rolled out and new variants are being discovered, one of the optimal ways to reduce morbidity and mortality due to COVID-19 is still to prevent the spread of the virus in the first place followed by symptomatic care of confirmed mild cases as well as supportive care, coupled with supplementary oxygen, ventilatory support, potentially immune modulators and possibly empiric antibiotics for more severe cases $[10,16]$. This is because COVID-19 is transmitted from person to person principally through respiratory droplets; consequently, initiatives to reduce prevalence rates include social distancing measures, facemasks, lockdowns, closure of borders and quarantining returning travellers $[3,17,18]$. Preventative messages generally appear well accepted by the population although there are concerns with current levels of misinformation about the disease and its consequences $[3,5,19]$. This includes hydroxychloroquine where there is still no concrete evidence showing prevention of COVID-19 [20].

African and Asian countries including Ghana, Malaysia, Namibia, South Korea, Taiwan and Vietnam were very proactive with a range of measures early in the pandemic, which resulted in limited prevalence and mortality rates certainly initially $[4,6,8,21]$. This compares with a number of European countries including Italy, Spain, and the United Kingdom (UK), where lockdown measures were typically introduced later once the pandemic had taken hold [7, 22, 23]. These delays may well have contributed to appreciably higher mortality rates in these three European countries initially than those seen among a number of African and Asian countries [2]. Overall by 8 November 2020, there were less deaths across the whole of WHO Africa than seen in either Italy, Spain or the UK alone, although there may be under reporting in some African countries $[2,3]$.

The lack of testing equipment, Personal Protective Equipment (PPE), intensive care unit beds and ventilators was a concern across Africa certainly initially [3]. These concerns resulted in many innovative developments across Africa including developing hands-free sanitisers (Uganda), low cost rapid testing equipment (Senegal, Uganda), a fingerprick blood test to rapidly detect antibodies (Ghana), mobile Apps for tracing people and improving patient experiences with COVID 19 (Kenya, South Africa), low cost face shields and splash protection masks (South Africa) as well as making ventilators/ noninvasive respirators (Kenya, South Africa) [3, 6, 8]. We believe these developments along with comprehensive measures helped reduce infection and mortality rates across Africa despite concerns with ethnicity and increased mortality rates from COVID-19 seen in a number of countries including the UK $[24,25]$.

There was considerable hype initially surrounding hydroxychloroquine with or without antimicrobials driven by a desire of governments and others to be seen as pro-active despite concerns with the robustness of early studies [3, 26], which resulted in shortages and associated price hikes for antimalarial medicines combined with suicides in a number of countries $[4,21,27]$. Recent studies though have failed to show any clinical benefit from hydroxychloroquine for the prevention or treatment of COVID-19 across settings [20, 28-30]. However, we are aware that hydroxychloroquine is still recommended for prevention and treatment of COVID-19 in some countries including Ghana, India and Malaysia initially despite concerns $[4,21,31]$. There is a similar situation surrounding concerns with lopinavir/ritonavir and remdesivir [32-35].

In view of the conflicting findings for a number of suggested medicines, there is a need for all key stakeholder groups to employ the principals of evidence-based medicine when reviewing or recommending treatments [5]. This is because early premature recommendations are a concern not only because they raise false hopes especially among patients, and potentially lead to citizens questioning the accuracy of subsequent guidance and advice from authorities, but false information also potentially exposes patients to severe adverse drug reactions as seen with hydroxychloroquine including potential cardiac side-effects [36, 37], and potentially enhances antimicrobial resistance (AMR) rates, which is already a concern across Africa [38]. AMR rates are enhanced especially among countries with high rates of selfpurchasing of antibiotics given high utilisation rates of antimicrobials in patients with COVID-19 despite the possibility of concomitant bacterial infections occurring in less than $4 \%$ of patients with COVID-19 [27, 39-41]. Alongside this, we are aware there are concerns with inappropriate use of medicinal plants to prevent and treat COVID-19 in view of their potential harm [42].

Namibia has a universal healthcare system, with the provision of well accepted guidelines to aid care delivery and typically monitoring of physician prescribing against current guidance. In addition, regulations banning the self-purchasing of antimicrobials [43-45]. This compares with for instance Nigeria with high co-payment levels and potentially catastrophic consequences for families when members become ill and with high rates of self-purchasing of antimicrobials in pharmacies $[3,4,46]$.

The vacuum with the lack of recommended treatments for COVID-19 with the potential exception of immune modulators such as coticosteroids has resulted in companies and others exploiting the opportunity with misinformation including herbal medicines [5, 42]. Misinformation regarding hydroxychloroquine has resulted, as mentioned, in appreciable increases in its utilisation, price hikes, shortages and suicides among a number of low- and 
middle-income countries (LMICs) [4, 21, 27, 47]. Any appreciable increase in antibiotic utilisation as a result of misinformation surrounding COVID-19 is also a concern since, as also mentioned, this increases AMR rates $[38,40,41]$.

Community pharmacists can play a key role during any pandemic especially among LMICs providing patients with important information regarding prevention measures including hygiene and social distancing [48, 49]. In addition, helping address misinformation through evidence-based approaches, helping with immunisation programmes if children cannot get to clinics, helping patients with chronic noncommunicable diseases (NCDs) to obtain their medicines during any lockdown as well as addressing key issues such as adherence to prescribed medicines for patients with NCDs unable to attend clinics [3, 21, 48].

We are aware that a number of community pharmacists were proactive in Namibia at the start of the COVID-19 pandemic building on the general preparadness of the country towards the pandemic [3]. Consequently, we wanted to determine changes in utilisation patterns, shortages and prices for potential medicines and PPE that could be used to prevent and treat COVID-19 in the early stages of the pandemic to guide future strategies in Namibia and wider. This also includes changes in the utilisation and prices of herbal medicines. In addition, ascertain potential future activities that community pharmacists could undertake to improve the care of patients during any pandemic. This is because we are aware of the many unintended consequences from lockdown and other measures to reduce the spread of COVID-19 on morbidity and mortality of other infectious diseases as well as NCDs. This is particularly important in sub-Saharan Africa given the high rates of both infectious and noninfectious diseases $[3,50,51]$.

\section{MATERIALS AND METHODS}

We adopted a similar comprehensive strategy to previous studies undertaken across Asia including Bangladesh and India, as well as African countries including Kenya, regarding utilisation and pricing strategies for pertinent medicines and equipment to prevent and treat COVID 19 combined with knowledge gained regarding ongoing activities across Africa to prevent and treat COVID-19 [3, 6, 21, 31]. This included a questionnaire survey among community pharmacies in Namibia to assess the current situation regarding usage patterns, prices, and availability of selected medicines potentially used in prevention and management of COVID-19 including antimalarials (hydroxychloroquine), antibiotics including azithromycin, analgesics, vitamins and herbal medicines along with PPE [6, 21, 27]. This typically included impressions from early March, i.e., just before the first patients with COVID-19 were identified in Namibia, to the end of June 2020 if this was the only information available (Table 1) since we were aware of issues such as confidentiality and no pharmacist was being paid for data collection.

Convenience sampling was used to select pharmacists through a variety of contact means including emails, telephone and personal contacts. Similar to studies across Asia and Kenya, there was no sample size calculation with no previous published data to base calculations upon $[4,21,27,31]$. All questions were open ended with data captured onto Excel spreadsheets. We also explored the preparedness of the pharmacists in Namibia to the pandemic (Table 1 and Appendix 1). Potential future guidance for key stakeholder groups will build on the experiences of those working in community pharmacists in Namibia combined with the experiences of the senior level coauthors as well as previous suggestions documented in Ogunleye et al. (2020) [3]. Data on the unintended consequences will be drawn from publications known to the co-authors.

Table-1: Key questions to those working in community pharmacies in Namibia including their preparedness for COVID-19 pandemic

\begin{tabular}{|l|l|}
\hline Activity & Summary questions \\
\hline $\begin{array}{l}\text { General questions } \\
\text { community } \\
\text { pharmacists from the } \\
\text { beginning of March } \\
\text { until the end of June } \\
2020 \text { (baseline early } \\
2020 \text { ) }\end{array}$ & $\begin{array}{l}\text { Changes in purchasing/ utilisation patterns for antimalarials (hydroxychloroquine), antibiotics (e.g. } \\
\text { azithromycin), multivitamins including vitamin C, analgesics and herbal medicines (where pertinent) - } \\
\text { information on invoices where possible or other information sources; otherwise, impressions } \\
\text { Similarly regarding any changes in the prices for these medicines as well as any shortages. If shortages, } \\
\text { what has been the extent if known? } \\
\text { Similarly, for PPE including face masks and other equipment such as hand sanitisers }\end{array}$ \\
\hline $\begin{array}{l}\text { Key questions } \\
\text { regarding the } \\
\text { preparedness of } \\
\text { community } \\
\text { pharmacists }\end{array}$ & $\begin{array}{l}\text { Key measures and interventions that the pharmacy has instigated to prevent the spread of the virus } \\
\text { (maximum of three from a pre-arranged list of seven activities based on the knowledge and experience of } \\
\text { the co-authors) } \\
\text { Suggestions regarding the potential and future role pharmacists/pharmaceutical technicians/pharmacist } \\
\text { assistants during pandemics (again up to three from a pre-arranged list of five potential activities) } \\
\text { The main challenges that pharmacy personnel experience during any pandemic (again a maximum of } \\
\text { three from a pre-arranged list of seven possible activities) } \\
\text { Potential future guidance for governments, pharmacists and patients going forward regarding future } \\
\text { pandemics building on your experiences }\end{array}$ \\
\hline
\end{tabular}


Dan Kibuule et al., Sch Acad J Pharm, May, 2021; 10(5): 82-92

The findings will be consolidated into categories in a tabular format to aid comparisons between Namibia and other African and Asian countries including Bangladesh, Ghana, Kenya, India and Nigeria with their high co-payment levels and potential catastrophic consequences when family members become ill $[6,21,27]$. We believe that increases in the utilisation, prices and shortages of antimalarials and antibiotics would be more limited in Namibia versus for instance Bangladesh and Nigeria with stricter controls in Namibia over the self-purchasing of antimicrobials. We believe this would also match the situation in Kenya where the availability of trained pharmacists helps reduce the dispensing of antibiotics for essentially viral infections including COVID-19 [4, 52]. However, similar concerns with the availability of vitamins and usage of herbal medicines in Namibia versus a number of other African and Asian countries.

\subsection{Ethical clearance information}

Ethical approval was obtained from the Ministry of Health and Social Services, Research and Ethics Committee in Namibia. This is different to previous studies undertaken by the co-authors in this and related areas including papers on prices of medicines for COVID-19 and potential ways forward across countries with no patient involvement $[3,4,6$, $21,27,31,53]$.

\section{RESULTS}

\subsection{Changes in utilisation, prices and shortages of targeted medicines and PPE}

Overall, 55 public and private pharmacies from 10 out of the 14 regions in Namibia took part in the study, which included pharmacies in rural (18.2\%), semi-urban $(29.1 \%)$ and urban settings $(52.7 \%)$. Data on utilisation, prices and shortages of pertinent medicines and PPE for COVID-19 was discussed before discussing issues of prepardness and the unintended consequences.

Table 2 documents changes in utilisation patterns for the various categories of medicines and PPE during the course of the study, Table 3 prices changes and Table 4 data on shortages.

Table-2: Changes in the utilisation of identified medicines and PPE among surveyed pharmacies $(n=55)$

\begin{tabular}{|l|c|c|c|c|c|c|}
\hline Change & AM & AB & AG & Vit C & HM & PPE \\
\hline Not known/ unrecorded & & & & & 33 & \\
\hline No change & 45 & 40 & 32 & 13 & 11 & \\
\hline $\begin{array}{l}\text { Increase (not specified) to slight increase } \\
(\leq 10 \%) / \text { high demand }\end{array}$ & 1 & 6 & 8 & 2 & 3 & 1 \\
\hline High increase to under 1.5 fold increase (<50\%) & 6 & 3 & 12 & 22 & 7 & 6 \\
\hline 1.5 fold to 3 fold increase & 3 & 6 & 3 & 18 & 1 & 48 \\
\hline Total (number) & $\mathbf{5 5}$ & $\mathbf{5 5}$ & $\mathbf{5 5}$ & $\mathbf{5 5}$ & $\mathbf{5 5}$ & $\mathbf{5 5}$ \\
\hline \% no change & $\mathbf{8 1 . 8}$ & $\mathbf{7 2 . 7}$ & $\mathbf{5 8 . 2}$ & $\mathbf{2 3 . 6}$ & $\mathbf{2 0 . 0}$ & $\mathbf{0 . 0}$ \\
\hline
\end{tabular}

$\mathrm{NB}: \mathrm{AM}=$ antimalarials, $\mathrm{AB}=$ antibiotics, $\mathrm{AG}=$ analgesics, Vit $\mathrm{C}=$ Vitamin $\mathrm{C}$ and other immune boosters; $\mathrm{HM}=$ herbal medicines; $\mathrm{PPE}=$ Personal protective equipment

Table-3: Changes in prices of identified medicines and PPE among surveyed community pharmacies $(\mathbf{n}=\mathbf{5 5})$

\begin{tabular}{|c|c|c|c|c|c|c|}
\hline Change & AM & $A B$ & AG & Vit C & HM & PPE \\
\hline Not known/ unrecorded & 33 & 33 & 33 & 33 & 33 & 28 \\
\hline No change & 20 & 19 & 18 & 5 & 20 & 1 \\
\hline $\begin{array}{l}\text { Increase (no specified) to slight increase } \\
(\leq 10 \%)\end{array}$ & 1 & 1 & 3 & 6 & 2 & \\
\hline High increase up to $<2$ fold increase & 1 & 2 & 1 & 11 & & 23 \\
\hline $2-4$ fold increase & & & & & & 3 \\
\hline Total (number) & 55 & 55 & 55 & 55 & 55 & 55 \\
\hline$\%$ recording increases & 3.6 & 5.5 & 7.3 & 30.9 & 3.6 & 47.3 \\
\hline
\end{tabular}

$\mathrm{NB}: \mathrm{AM}=$ antimalarials, $\mathrm{AB}=$ antibiotics, $\mathrm{AG}=$ analgesics, $\mathrm{Vit} \mathrm{C}=$ Vitamin $\mathrm{C}$ and other immune boosters; $\mathrm{HM}=$ herbal medicines; $\mathrm{PPE}=$ Personal protective equipment

Table-4: Shortages of identified medicines and PPE among surveyed comminity pharmacies $(n=55)$

\begin{tabular}{|l|c|c|c|c|c|c|}
\hline Change & AM & AB & AG & Vit C & HM & PPE \\
\hline Available/ no shortages/ not dispensed & 38 & 38 & 49 & 31 & 17 & 13 \\
\hline Not known/ unrecorded & & & & & 33 & \\
\hline Shortages & 17 & 17 & 6 & 24 & 5 & 42 \\
\hline Total (number) & $\mathbf{5 5}$ & $\mathbf{5 5}$ & $\mathbf{5 5}$ & $\mathbf{5 5}$ & $\mathbf{5 5}$ & $\mathbf{5 5}$ \\
\hline \% No Shortages & $\mathbf{6 9 . 1}$ & $\mathbf{6 9 . 1}$ & $\mathbf{8 9 . 1}$ & $\mathbf{5 6 . 4}$ & $\mathbf{9 0 . 9}$ & $\mathbf{2 3 . 6}$ \\
\hline
\end{tabular}

$\mathrm{NB}: \mathrm{AM}=$ antimalarials, $\mathrm{AB}=$ antibiotics, $\mathrm{AG}=$ analgesics, Vit $\mathrm{C}=$ Vitamin $\mathrm{C}$ and other immune boosters; $\mathrm{HM}=$ herbal medicines; $\mathrm{PPE}=$ Personal protective equipment 


\subsection{Activities among community pharmacies in response to the COVID-19 pandemic, challenges and suggested future activities}

Among the community pharmacies taking part, 15 (27.3\%) stated they were prepared for the pandemic through bulk ordering possible medicines as well as PPE and hand sanitizers/disinfectants in anticipation of increased demand, with 2 of these 15 also making arrangements for additional staff to cope with anticipated demand.

Overall, those working in community pharmacies in Namibia had put in place a number of measures to help curb the spread of COVID-19 with all pharmacies putting in place at least one measure, $92.7 \%$ at least 2 measures with $41.8 \%$ three measures (Box 1), which included activities for increased supply of medicines. $98.2 \%$ of those surveyed documented one challenge to address, $47.3 \%$ two challenges with two out of the 55 pharmacists and assistants documenting three challenges. $96.4 \%$ of the surveyed pharmacists, pharmaceutical technicians, and pharmacist assistants subsequently suggested one current and future potential role to reduce the spread of subsequent viruses, building on the challenges and activities to date, $50.1 \%$ two roles and one pharmacist three roles (Box 1).

Box 1 - Activities instigated among community pharmacies in Namibia to prevent the spread of COVID-19, challenges and potential roles ( $n$ - number of respondents)

(a) Activities to prevent the spread of the virus

Promoting sanitization/disinfection/handwashing -41 respondents

Social distancing protocols -30 respondents

Promoting personal protective equipment (PPE) -29 respondents

Multi-month dispensing of medicines -13 respondents

Temperature screening before entry and Name on a register -6 respondents each

Creating awareness -4 respondents

(b) Challenges

Inadequate stock of PPE - 41 respondents

Medicine stock-outs/ low stock -30 respondents

Shortage of sanitizers/disinfectants -29 respondents

Clients/staff not adhering to regulations -13 respondents

Inadequate space in pharmacy for staff to maintain social distancing -6 respondents

Increased workload due to initial panic buying and increased demand of items -6 respondents

Increments in medicine prices hence impact on finances -4 respondents

(c) Suggested activities for current and future pandemics

Educating and providing information on Covid-19 to the public -27 respondents

Advising on treatment plans for suspected infections as well as providing appropriate medicines -24 respondents

Ensuring adequate supply of PPE and hand sanitizers -14 respondents

Ensuring good stock control -10 respondents

Screening of patients that present to pharmacy and referring them for further testing if necessary -7 respondents

\subsection{Unintended consequences}

Unintended consequences across Africa include those for both infectious diseases and NCDs.

\subsubsection{Infectious diseases}

There are concerns that an appreciable reduction in the distribution of protective bed nets $(75 \%)$ and medicines for treating malaria due to lockdown measures, combined with a lack of media campaigns with the continued focus on COVID-19, could result in up to 18 million additional cases and up to 30,000 additional deaths in sub-Saharan Africa from malaria alone compared to 2018 [3]. Such unintended consequences must be factored into future considerations when reviewing potential approaches to future pandemics.

Abbas et al. recently estimated that for every one excess COVID-19 death attributable to COVID-19 infections acquired during routine vaccination clinic visits with no catch up campaigns, 84 deaths could be prevented among children under 5 in Africa due to tetanus, diphtheria, pertussis, meningitis A, rotavirus, rubella, hepatitis B, Haemophilus influenzae type b, Streptococcus pneumoniae, measles, and yellow fever [54].

Ongoing national action plans across Africa and wider to reduce AMR through high rates of inappropriate antimicrobial prescribing and any associated morbidity and mortality could also be postponed with a focus on COVID-19 activities [38]. This urgently needs to be addressed given high inappropriate prescribing and dispensing of antibiotics for patients with COVID-19 across countries [40].

\subsubsection{Non-communicable diseases}

There are increasing concerns that lockdown and other measures will negatively impact on the management of patients with NCDs due to a lack of support and access to facilities for diagnosis, lifestyle advice, monitoring of outcomes and providing essential 
medicines [3]. Ongoing national plans across Africa to reduce the morbidity and mortality associated with NCDs, including CVD and diabetes, will also be compromised by reduced access to medicines, cancelled or missed appointments and patients not following lifestyle advice [3, 50]. However, there are ongoing measures to extend prescription lengths across Africa, undertake home deliveries as well as potentially undertake patient consultations through telemedicine and other technologies [3]. In addition, review potential treatments for patients with diabetes requiring insulin across continents including African countries [55, 56].

Other serious consequences of COVID-19 include exacerbation of mental health conditions as a result of lockdown measures as well as the stigma associated with COVID-19 [3]. These issues also need to be researched in more detail to help build a comprehensive picture of both intended and unintended consequences of introducing a variety of measures to tackle any future pandemic.

\section{DISCUSSION}

Early lockdown and other measures appear essential to prevent the spread of COVID-19 as seen among a number of African and Asian countries versus European countries [3-5, 21, 31]. However, such activities must be balanced against the unintended consequences during pandemics (Section 3.3).

Encouragingly in Namibia, there was typically no change in the utilisation of antibiotics and antimalarials in the initial months following the pandemic. We believe this was helped by monitoring of pharmacies and their awareness of current regulations banning self-purchasing. However, we cannot say this for certainty without further research. This contrasts though with Nigeria where the utilisation of antimalarials increased by 3 to 5 -fold or more in $100 \%$ of the pharmacies surveyed and antibiotics by 1.5 -fold or more in $86.7 \%$ of those surveyed in the months following the start of the pandemic [47]. In addition in Ghana, $83.3 \%$ of the pharmacies surveyed reported increases up to 1.5 fold or more for antimalarials, with $100 \%$ of pharmacies reporting increases in antibiotic utilisation during the same period [6]. Increases in the utilisation of antimalarials and antibiotics were also seen in Bangladesh in the months following the pandemic, but these tended to be lower than seen in Ghana and Nigeria [27]. This was reflected in appreciable price rises for antimalarials and antibiotics soon after the start of the pandemic in Nigeria but not Ghana with only $33.3 \%$ of pharmacies noting increased prices [6, 47]. Any price rises may have been exacerbated by reported shortages in both countries [6, 47], and compare with very limited price rises and shortages in Namibia (Tables 3 and 4).

Self-purchasing of antibiotics is a particular concern across countries enhanced in this situation with the clinical presentation of COVID-19 overlapping with other infectious diseases including other respiratory tract infections and making differential diagnosis challenging $[3,38,40]$. Consequently, patients suspected of having COVID-19 should be asked to make health declarations in pharmacies and be referred to a treatment centre if needed, which build on initiatives in Vietnam [21]. In addition, there is a need to educate pharmacists and patients generally in countries where there are concerns with the selfpurchasing of antimicrobials and fines are difficult to impose, building on initiatives in Kenya [4, 38].

There was also higher use of vitamin C/ immune boosters in Ghana and Nigeria $(100 \%$ of pharmacies) than seen in Namibia (76.4\%) with a resultant greater price rises among surveyed pharmacies in Ghana and Nigeria, with a similar picture in Bangladesh [4, 27]. However, it was encouraging to see growth in their use in Namibia.

There was a greater increase in the use of analgesics in Namibia than either Ghana, Nigeria, or Bangladesh in the months after the start of the pandemic; however, prices remained relatively stable in Namibia which is encouraging [6, 21, 27]. There was limited change in the utilisation of herbal medicines in Namibia compared with Ghana during the study period, which is again encouraging and may reflect greater use generally of herbal medicines in Ghana although this remains to be proven [6]. Perhaps not surprising, the higher use of herbal medicines in Ghana resulted in greater price rises as well as shortages versus Namibia [6]. As expected, there was increased utilisation of PPE across all studied countries with associated price rises and shortages in some pharmacies, with prices rises appreciably higher in Nigeria than seen in Namibia, which is welcomed $[4,6,21]$.

Potential ways forward for pharmacists to improve the care of patients during pandemics and better plan for the future are contained in Box 1. We are likely to see an increasing role for community pharmacists in the future especially with immunisation programmes and improved management of patients with NCDs to reduce the unintended consequences with their associated increase in morbidity and mortality. We will be researching and monitoring this further in the future. For governments and other key stakeholder groups, there is an urgent need to enhance an evidencebased approach to reduce the level of misinformation and its consequences surrounding the pandemic. We have started to see African countries introduce fines and potential imprisonment for companies and organisations providing misinformation [3], and this is likely to continue.

\section{Limitations}

We are aware of a number of limitations with this study. This includes the fact that we were unable to 
Dan Kibuule et al., Sch Acad J Pharm, May, 2021; 10(5): 82-92

gain precise knowledge of changes in utilisation, prices and shortages among a number of the pharmacies surveyed. However, we believe the information provided is robust and provides direction for the future not only in Namibia but wider.

\section{CONCLUSION}

Encouragingly in Namibia, there were limited increases in the utilisation and prices of antimalarials and antibiotics since the start of the pandemic aided by regulations banning self-purchasing of antimicrobials. This is particularly important given concerns with rising AMR rates across Africa, and can serve as an example to other African countries. There were also lower increases in the use of herbal medicines in Namibia than seen for instance in Ghana, which is again encouraging given concerns with their use especially in patients with COVID-19 until more data is available. Unsurprisingly, there was increased use of vitamin C and PPE across Africa and Asia, with though lower rises in Namibia.

Community pharmacists can be proactive in preparing effectively for future pandemics although further research is needed surrounding the unintended consequences to fully appreciate any future role. These are projects for the future.

\section{Funding and conflicts of interest}

There was no funding for this paper and all authors declare they have no conflicts of interest.

\section{REFERENCES}

1. Wu, Z., \& McGoogan, J. M. (2020). Characteristics of and important lessons from the coronavirus disease 2019 (COVID-19) outbreak in China: summary of a report of 72314 cases from the Chinese Center for Disease Control and Prevention. Jama, 323(13), 1239-1242.

2. WHO. (2020). Weekly epidemiological update COVID-19 - 10 November 2020. Available at URL:

https://www.who.int/publications/m/item/weeklyepidemiological-update---10-november-2020.

3. Ogunleye, O. O., Basu, D., Mueller, D., Sneddon, J., Seaton, R. A., Yinka-Ogunleye, A. F., ... \& Godman, B. (2020). Response to the novel corona virus (COVID-19) pandemic across Africa: successes, challenges, and implications for the future. Frontiers in pharmacology, 11, 1205.

4. Opanga, S. A., Rizvi, N., Wamaitha, A., Sefah, I. A., \& Godman, B. (2021). Availability of medicines in community pharmacy to manage patients with COVID-19 in Kenya; pilot study and implications. Scholars Academic Journal of Pharmacy, 10(3), 36-43.

5. Godman, B. (2020). Combating COVID-19: Lessons learnt particularly among developing countries and the implications. Bangladesh Journal of Medical Science, 103-S.
6. Sefah, I., Ogunleye, O., Essah, D., Opanga, S., Rizvi, N., Wamaitha, A., ....\& Godman, B (2021). Rapid assessment of the potential paucity and price increases for suggested medicines and protection equipment for COVID-19 across developing countries with a particular focus on Africa and the implications. Frontiers in pharmacology, 11, 2055.

7. Anderson, R. M., Hollingsworth, T. D., Baggaley, R. F., Maddren, R., \& Vegvari, C. (2020). COVID19 spread in the UK: the end of the beginning?. The Lancet, 396(10251), 587-590.

8. Afriyie, D. K., Asare, G. A., Amponsah, S. K., \& Godman, B. (2020). COVID-19 pandemic in resource-poor countries: challenges, experiences and opportunities in Ghana. The Journal of Infection in Developing Countries, 14(08), 838843.

9. Horby, P., Lim, W.S., Emberson, J.R., Mafham, M., Bell, J.L., Linsell, L. (2021). Dexamethasone in Hospitalized Patients with Covid-19. N Engl J Med, 384(8):693-704.

10. Abubakar, A. R., Sani, I. H., Godman, B., Kumar, S., Islam, S., Jahan, I., \& Haque, M. (2020). Systematic Review on the Therapeutic Options for COVID-19: Clinical Evidence of Drug Efficacy and Implications. Infection and drug resistance, 13, 4673.

11. Aziz, M., Haghbin, H., Abu Sitta, E., Nawras, Y., Fatima, R., Sharma, S., ... \& Assaly, R. (2021). Efficacy of tocilizumab in COVID- 19: a systematic review and meta- analysis. Journal of Medical Virology, 93(3), 1620-1630.

12. Baraniuk, C. (2021). Where are we with drug treatments for covid-19?. bmj, 373.

13. Chung, J. Y., Thone, M. N., \& Kwon, Y. J. (2020). COVID-19 vaccines: The status and perspectives in delivery points of view. Advanced drug delivery reviews.

14. Hacisuleyman, E., Hale, C., Saito, Y., Blachere, N. E., Bergh, M., Conlon, E. G., ... \& Darnell, R. B. (2021). Vaccine Breakthrough Infections with SARS-CoV-2 Variants. New England Journal of Medicine.

15. Ray, S. (2021). AstraZeneca and Pfizer Covid-19 Vaccines More Than 86\% Effective After First Dose, South Korean Authorities Say. 2021. Available at URL: https://www.forbes.com/sites/siladityaray/2021/05/ 05/astrazeneca-and-pfizer-covid-19-vaccines-morethan-86-effective-after-first-dose-south-koreanauthorities-say/?sh=5936e1614f32.

16. BMJ Best Practice - Coronavirus disease 2019 (COVID-19). 8 April 2021. Available at URL: https://bestpractice.bmj.com/topics/en-gb/3000201.

17. Pradhan, D., Biswasroy, P., Naik, P. K., Ghosh, G., \& Rath, G. (2020). A review of current interventions for COVID-19 prevention. Archives of medical research, 51(5), 363-374.

18. Chu, D. K., Akl, E. A., Duda, S., Solo, K., Yaacoub, S., Schünemann, H. J., ... \& Reinap, M. 
Dan Kibuule et al., Sch Acad J Pharm, May, 2021; 10(5): 82-92

(2020). Physical distancing, face masks, and eye protection to prevent person-to-person transmission of SARS-CoV-2 and COVID-19: a systematic review and meta-analysis. The Lancet, 395(10242), 1973-1987.

19. Hayat, K., Rosenthal, M., Xu, S., Arshed, M., Li, P., Zhai, P., ... \& Fang, Y. (2020). View of Pakistani residents toward coronavirus disease (COVID-19) during a rapid outbreak: a rapid online survey. International journal of environmental research and public health, 17(10), 3347.

20. Smit, M., Marinosci, A., Agoritsas, T., Ford, N., \& Calmy, A. (2021). Prophylaxis for COVID-19: a systematic review. Clinical Microbiology and Infection.

21. Godman, B., Haque, M., Islam, S., Iqbal, S., Urmi, U. L., Kamal, Z. M., ... \& Hossain, M. M. (2020). Rapid assessment of price instability and paucity of medicines and protection for COVID-19 across Asia: findings and public health implications for the future. Frontiers in public health, 8 .

22. Schnirring, L. (2020). Italy expands COVID-19 lockdown to whole country. 9 March 2020. Available at URL: https://www.cidrap.umn.edu/newsperspective/2020/03/italy-expands-covid-19lockdown-whole-country.

23. Jones, J. (2020). Spanish PM announces stricter lockdown measures to tackle coronavirus. 28 March 2020. Available at URL: https://www.reuters.com/article/us-healthcoronavirus-spain/spanish-pm-announces-stricterlockdown-measures-to-tackle-coronavirusidUSKBN21F0NR.

24. Pan, D., Sze, S., Minhas, J. S., Bangash, M. N., Pareek, N., Divall, P., ... \& Pareek, M. (2020). The impact of ethnicity on clinical outcomes in COVID-19: a systematic review. EClinicalMedicine, 23, 100404.

25. Public Health England. (2020). Disparities in the risk and outcomes of COVID-19. 2020. Available at URL: https://assets.publishing.service.gov.uk/government /uploads/system/uploads/attachment_data/file/8920 85/disparities_review.pdf.

26. International Society of Antimicrobial Chemotherapy. Official Statement from International Society of Antimicrobial Chemotherapy (ISAC) - Hydroxychloroquine and azithromycin as a treatment of COVID-19: results of an open-label non-randomized clinical trial (Gautret P et al. PMID 32205204). Available at URL: https://www.isac.world/news-andpublications/official-isac-statement.

27. Haque, M., Islam, S., Iqbal, S., Urmi, U. L., Kamal, Z. M., Rahman, A., ... \& Godman, B. (2020). Availability and price changes of potential medicines and equipment for the prevention and treatment of COVID-19 among pharmacy and drug stores in Bangladesh; findings and implications. Bangladesh Journal of Medical Science, 36-S.

28. Horby, P., Mafham, M., Linsell, L., Bell, J. L., Staplin, N., Emberson, J. R., ... \& Landray, M. J. (2020). Effect of Hydroxychloroquine in Hospitalized Patients with COVID-19: Preliminary results from a multi-centre, randomized, controlled trial. MedRxiv.

29. Pan, H., Peto, R., Henao-Restrepo, A.M., Preziosi, M.P., Sathiyamoorthy, V., Abdool, K. Q. (2021). Repurposed Antiviral Drugs for Covid-19 - Interim WHO Solidarity Trial Results. N Engl J Med, 384(6):497-511.

30. Saghir, S. A., AlGabri, N. A., Alagawany, M. M., Attia, Y. A., Alyileili, S. R., Elnesr, S. S., ... \& Abd El-Hack, M. E. (2021). Chloroquine and Hydroxychloroquine for the Prevention and Treatment of COVID-19: A Fiction, Hope or Hype? An Updated Review. Therapeutics and Clinical Risk Management, 17, 371.

31. HAQUE, M., Kumar, S., Charan, J., Bhatt, R., Islam, S., Dutta, S., .. \& Godman, B. (2020). Utilisation, availability and price changes of medicines and protection equipment for COVID-19 in India: findings and implications Short title: COVID-19 and price changes of treatments in India. Frontiers in pharmacology, 11, 1822.

32. Lopinavir-ritonavir in patients admitted to hospital with COVID-19 (RECOVERY). (2020). A randomised, controlled, open-label, platform trial. Lancet, 396(10259):1345-52.

33. WHO. (2020). WHO discontinues hydroxychloroquine and lopinavir/ritonavir treatment arms for COVID-19. 4 July 2020. Available at URL: https://www.who.int/newsroom/detail/04-07-2020-who-discontinueshydroxychloroquine-and-lopinavir-ritonavirtreatment-arms-for-covid-19.

34. Dyer, O. (2020). Covid-19: Remdesivir has little or no impact on survival, WHO trial shows. BMJ, 371:m4057.

35. Charan, J., Kaur, R. J., Bhardwaj, P., Haque, M., Sharma, P., Misra, S., \& Godman, B. (2021). Rapid review of suspected adverse drug events due to remdesivir in the WHO database; findings and implications. Expert review of clinical pharmacology, 14(1), 95-103.

36. Das, S., Bhowmick, S., Tiwari, S., \& Sen, S. (2020). An updated systematic review of the therapeutic role of hydroxychloroquine in coronavirus disease-19 (COVID-19). Clinical drug investigation, 40, 591-601.

37. Mercuro, N. J., Yen, C. F., Shim, D. J., Maher, T. R., McCoy, C. M., Zimetbaum, P. J., \& Gold, H. S. (2020). Risk of QT interval prolongation associated with use of hydroxychloroquine with or without concomitant azithromycin among hospitalized patients testing positive for coronavirus disease 
2019 (COVID-19). JAMA cardiology, 5(9), 10361041.

38. Godman, B., Haque, M., McKimm, J., Abu Bakar, M., Sneddon, J., Wale, J., ... \& Hill, R. (2020). Ongoing strategies to improve the management of upper respiratory tract infections and reduce inappropriate antibiotic use particularly among lower and middle-income countries: findings and implications for the future. Current medical research and opinion, 36(2), 301-327.

39. Rawson, T. M., Moore, L. S., Zhu, N., Ranganathan, N., Skolimowska, K., Gilchrist, M., ... \& Holmes, A. (2020). Bacterial and fungal coinfection in individuals with coronavirus: a rapid review to support COVID-19 antimicrobial prescribing. Clinical Infectious Diseases, 71(9), 2459-2468.

40. Hsu, J. (2020). How covid-19 is accelerating the threat of antimicrobial resistance. BMJ, 369.

41. Langford, B. J., So, M., Raybardhan, S., Leung, V., Soucy, J. P. R., Westwood, D., ... \& MacFadden, D. R. (2021). Antibiotic prescribing in patients with COVID-19: rapid review and metaanalysis. Clinical Microbiology and Infection.

42. Yang, Y. (2020). Use of herbal drugs to treat COVID-19 should be with caution. The Lancet, 395(10238), 1689-1690.

43. Kamati, M., Godman, B., \& Kibuule, D. (2019). Prevalence of self-medication for acute respiratory infections in young children in Namibia: findings and implications. Journal of research in pharmacy practice, 8(4), 220.

44. Nashilongo, M. M., Singu, B., Kalemeera, F., Mubita, M., Naikaku, E., Baker, A., ... \& Kibuule, D. (2017). Assessing adherence to antihypertensive therapy in primary health care in Namibia: findings and implications. Cardiovascular drugs and therapy, 31(5), 565-578.

45. Niaz, Q., Godman, B., Campbell, S., Kibuule, D. (2020). Compliance to prescribing guidelines among public health care facilities in Namibia; findings and implications. International journal of clinical pharmacy, 42(4):1227-36.

46. Aregbeshola, B.S., Khan, S.M. (2018). Out-ofPocket Payments, Catastrophic Health Expenditure and Poverty among Households in Nigeria 2010. International journal of health policy and management, 7(9):798-806.

47. Haque, M., Abubakar, A., Ogunleye, O., Sani, I., Sefah, I., Kurdi, A., ......Godman, B (2021). Changes in availability, utilization, and prices of medicines and protection equipment for COVID-19 in an Urban population of Northern Nigeria.
Journal of Research in Pharmacy Practice, 10(1):17-22.

48. Cadogan, C. A., \& Hughes, C. M. (2021). On the frontline against COVID-19: Community pharmacists' contribution during a public health crisis. Research in Social and Administrative Pharmacy, 17(1), 2032-2035.

49. Adunlin, G., Murphy, P. Z., \& Manis, M. (2020). COVID- 19: how can rural community pharmacies respond to the outbreak?. The Journal of Rural Health.

50. Godman, B., Basu, D., Pillay, Y., Mwita, J. C., Rwegerera, G. M., Paramadhas, B. D. A., ... \& Meyer, J. C. (2020). Review of ongoing activities and challenges to improve the care of patients with type 2 diabetes across Africa and the implications for the future. Frontiers in pharmacology, 11.

51. Rampamba, E. M., Meyer, J. C., Helberg, E. A., \& Godman, B. (2019). Empowering hypertensive patients in South Africa to improve their disease management: a pharmacist-led intervention. Journal of research in pharmacy practice, 8(4), 208.

52. Mukokinya, M. M. A., Opanga, S., Oluka, M., \& Godman, B. (2018). Dispensing of antimicrobials in Kenya: A cross-sectional pilot study and its implications. Journal of research in pharmacy practice, 7(2), 77.

53. Haque, M., Islam, S., Kamal, Z. M., Akter, F., Jahan, I., Rahim, M. S. A., ... \& Godman, B. (2021). Ongoing efforts to improve the management of patients with diabetes in Bangladesh and the implications. Hospital practice, 1-7.

54. Abbas, K., Procter, S.R., van, Zandvoort, K., Clark, A., Funk, S., Mengistu, T. (2020). Routine childhood immunisation during the COVID-19 pandemic in Africa: a benefit-risk analysis of health benefits versus excess risk of SARS-CoV-2 infection. The Lancet Global health, 8(10):e1264e72.

55. Godman, B., Haque, M., Leong, T., Allocati, E., Kumar, S., Islam, S. (2021). The current situation regarding long-acting insulin analogues including biosimilars among selected African, Asian, European and South American countries: findings and implications for the future. 2021 Accepted for publication Frontiers in Public Health -doi: 10.3389/fpubh.2021.671961.

56. Opanga, S., Njeri, L.W., Kimonge, D., Godman, B., Oluka, M. (2021). Assessing Utilisation and Expenditure on Long-Acting Insulin Analogues in Kenya; Findings and Implications for the Future. Sch Acad J Pharm, 10(4): 63-70. 


\section{Appendix - Questionnaire used in Namibia}

101. Location of the pharmacy/dispensary?

- Region:

- Setting: (1) $\square$ Rural (2) $\square$ semi urban (3) $\square$ urban

- Facility type: (1) $\square$ Private (2) $\square$ Public

102. Was the pharmacy prepared for this pandemic?

1-Yes 2- No

If yes, how?

1- Bulk ordering of medicines, sanitizers/disinfectants and PPE

2- Made arrangements for enough staff to be available

103. What key measures/interventions has the pharmacy put in place during this pandemic to curb the spread of COVID-19 in the community?

- Sanitization/disinfection/handwashing

- Social distancing protocols

- Personal protective equipment

- $\quad$ Temperature screening before entry

- Name register

- Multi-month dispensing

- Creating awareness

104. Itemize suggestions on the role (current and new) of pharmacist/pharmaceutical technicians/pharmacist assistant during this pandemic

- Educating and providing information on Covid-19 to the public

- Advising on treatment plan as well as providing the medicines

- Screening of patients that present to pharmacy and referring them for further testing if necessary

- Supply PPE and sanitizers

- Stock control

105. What were the main challenges experienced by the pharmacy during the pandemic?

- Inadequate stock of PPE

- Medicine stock-outs/ low stock

- Shortage of sanitizers/disinfectants

- Inadequate space in pharmacy for staff to maintain social distancing

- Increased workload due to initial panic buying and increased demand of items

- Clients/staff not adhering to regulations

- Increments in medicine prices hence impact on finances

106. What INCREASE in SALES/DISPENSING/DEMAND have you noticed since the beginning of March on the following items? (Give examples of the commonest types and estimate the percentage change if any)

\begin{tabular}{|l|l|l|l|}
\hline & Tick for an increase $(\checkmark)$ & Increased by $(\%)$ & Specific Example \\
\hline Sanitizers/Disinfectants & & & \\
\hline Antimalarials & & & \\
\hline Antibiotics & & & \\
\hline Analgesics & & & \\
\hline Herbal medications & & & \\
\hline Multivitamins & & & \\
\hline Immune boosters & & & \\
\hline Cold and Flu medicines & & & \\
\hline Contraceptives & & & \\
\hline Other: & & & \\
------------------------- & & & \\
\hline
\end{tabular}


107. What INCREASES in medicine BUYING PRICE (increase/decrease) have you noticed since the beginning of March on the following medicines? (estimate the percentage change in price)

\begin{tabular}{|l|l|l|l|}
\hline & Tick for an increase $(\checkmark)$ & Increased by (\%) & Specific Example \\
\hline Sanitizers/Disinfectants & & & \\
\hline Antimalarials & & & \\
\hline Antibiotics & & & \\
\hline Analgesics & & & \\
\hline Herbal medications & & & \\
\hline Multivitamins & & & \\
\hline Immune boosters & & & \\
\hline Cold and Flu medicines & & & \\
\hline Contraceptives & & & \\
\hline Other: & & & \\
\hline------------------------ & & & \\
\hline
\end{tabular}

108. What SHORTAGE/NON-AVAILABILITY of the following items have you noticed since the beginning of March? (Estimate stock out period in weeks/months if any)

\begin{tabular}{|l|l|l|l|}
\hline & $\begin{array}{l}\text { Tick for stockout } \\
(\checkmark)\end{array}$ & $\begin{array}{l}\text { Estimated stockout } \\
\text { periods in Weeks/months }\end{array}$ & Specific Example \\
\hline Sanitizers/Disinfectants & & & \\
\hline Antimalarials & & & \\
\hline Antibiotics & & & \\
\hline Analgesics & & & \\
\hline Herbal medications & & & \\
\hline Multivitamins & & & \\
\hline Immune boosters & & & \\
\hline Cold and Flu medicines & & & \\
\hline Contraceptives & & & \\
\hline $\begin{array}{l}\text { Other: } \\
\text {------------------------- }\end{array}$ & & & \\
\hline
\end{tabular}

109. Which medicines/supplies in Namibia have experienced influx of fake/substandard/ spurious forms during this pandemic (if any)?

110.

\begin{tabular}{|c|c|}
\hline & Tick where applicable $(\checkmark)$ \\
\hline Sanitizers/Disinfectants & \\
\hline Antimalarials & \\
\hline Antibiotics & \\
\hline Analgesics & \\
\hline Herbal medications & \\
\hline Multivitamins & \\
\hline Immune boosters & \\
\hline Cold and Flu medicines & \\
\hline Contraceptives & \\
\hline Other: & \\
\hline
\end{tabular}

Thank you 